\title{
15 Plasticity and Evolutionary Theory: Where We Are and Where We Should Be Going
}

\author{
Carl D. Schlichting \\ University of Connecticut
}

\section{CONTENTS}

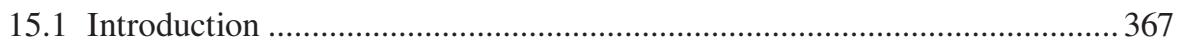

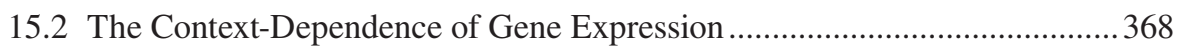

15.3 Plasticity May Be Ancestrally Ancestral......................................................369

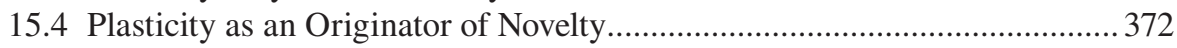

15.5 Genetic Accommodation and Plasticity-Led Evolution .................................. 374

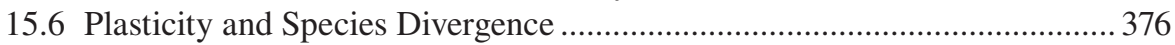

15.7 Plasticity Produces Distinctive Evolutionary Dynamics ................................ 378

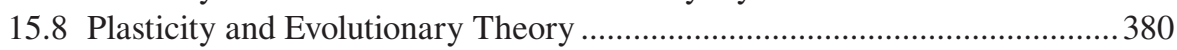

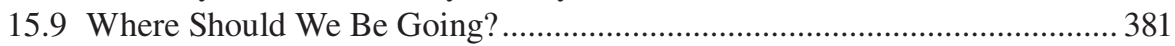

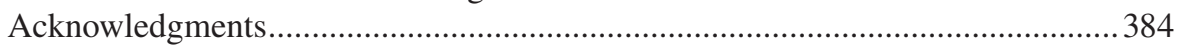

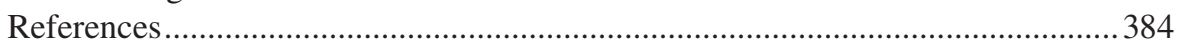

\subsection{INTRODUCTION}

Although the evolutionary importance of adaptive phenotypic plasticity as a mechanism of adaptation to spatial and temporal environmental variation is acknowledged as part of the mainstream of evolutionary theory, arguments for a broader importance of phenotypic plasticity are contentious, mainly hinging on its potential role as a facilitator of evolutionary change (see Futuyma 2021; Levis and Pfennig 2021; Pfennig 2021 in this volume). Some proponents of an enhanced role for plasticity have called for its inclusion as an important component of an 'extended evolutionary synthesis' (trait-specific changes to offspring phenotypes induced by parental environmental conditions; Pigliucci 2007; Laland et al. 2015).

In this chapter, I will show that plasticity has important ramifications for many aspects of evolutionary theory. I will highlight current research on several of these topics as a means of demonstrating the impacts of plasticity on a range of evolutionary processes. Subsequently, I will address the broader issue of how responses to 'environmental' variation can be more fully incorporated into our understanding of the evolution of phenotypes. 


\subsection{THE CONTEXT-DEPENDENCE OF GENE EXPRESSION}

Although we tend to forget this, gene expression is always context-dependent (Nijhout 1990). Genes require an environmental cue to be expressed whether that cue is an external environment or the product of some other gene, and phenotypes can vary as a function of differences in those cues (see examples in Sultan 2021 in this volume). So, while one can readily assign a fitness to a DNA sequence in a computer model, in the real world, it is that sequence's expressed phenotype that has a fitness. One consequence of this 'forgetting' is that we neglect the fact that patterns of gene expression leading to 'normal' development have evolved in the context of specific ranges and frequencies of various environmental parameters (Pei et al. 2020). When organisms are placed in environmental contexts beyond the scope of their evolutionary memory, their development may no longer be predictable.

Normal developmental sequences are often considered to be 'canalized' or 'robust' to genetic or environmental changes. Within the normal range of environments, novelties in canalized developmental pathways are most likely to be produced via mutation. However, outside of those environments where canalization has evolved, reaction norms are inherently plastic and thus also inherently prone to produce phenotypic novelty (hidden reaction norms: Schlichting and Pigliucci 1998; Schlichting 2003; Ghalambor et al. 2007; Schlichting 2008). 'Hidden reaction norms' (Figure 15.1) represent plastic responses to novel or infrequently experienced conditions for which there has been no selection for either canalization of a particular phenotype or an adaptive plastic response. Collectively, the hidden reaction norms of different genotypes express 'cryptic genetic variation' (Figure 15.1). Such cryptic genetic variation has been suggested to represent a store of variability that can be revealed in novel environments or genetic backgrounds (Gibson and Dworkin 2004; Le Rouzic and Carlborg 2008; Moczek 2008; Schlichting 2008; Paaby and Rockman 2014; Schneider and Meyer 2017; Donnelly et al. 2018; Zheng et al. 2019; Pilakouta et al. 2020).

Zan and Carlborg (2020) investigated the organization of 130 yeast growth regulation genes in response to 20 different growth media. They discovered that epistatic gene interactions were significantly reorganized across environments, with a few individual loci involved in epistatic interactions on as many as 16 different growth media, but the majority were expressed in fewer than four. Thus, there were different patterns of hidden and revealed growth-regulating loci contributing to plasticity and robustness across the different growth conditions.

Adaptive phenotypic plasticity represents a type of buffering at a different scalecanalization of responses of different genotypes to environmental shifts (e.g., the set of parallel horizontal reaction norms for flowering in Timberline and Mather; Figure 15.1). Convergence of responses on an adaptive reaction norm will also shield unexpressed genetic variants among those genotypes from selection (Wright 1931; Schwab et al. 2019). Signor (2020) documents the canalization of reaction norms in a comparison of ethanol tolerance in Drosophila simulans - possessing the ancestral non-tolerant phenotype - and D. melanogaster - with an evolved tolerance to ethanol. She finds substantial genetic variation in the reaction norms of gene expression to ethanol of $D$. simulans but no such variation in $D$. melanogaster, a lack of variation expected if an ethanol tolerant reaction norm had been strongly selected. 


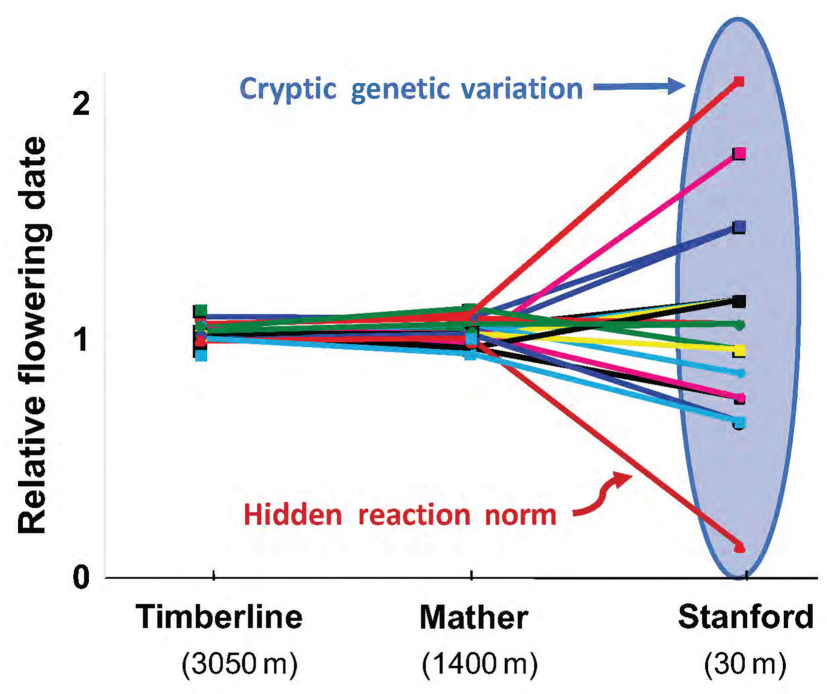

Transplant garden (elevation)

FIGURE 15.1 Graph of variation in relative flowering times of Potentilla glandulosa clones grown at three transplant gardens. Little variation is observed at the elevations where populations are normally found (i.e., at Timberline and Mather), and the reaction norm is itself canalized between these sites. However, at the sea level garden at Stanford, clones express hidden reaction norms resulting in the expression of significant cryptic genetic variation in this population. (Data from Clausen et al. [1940]; figure modified, with permission from The New York Academy of Sciences, John Wiley \& Sons, Inc., from Schlichting [2008].) A modern example of hidden reaction norms and cryptic genetic variation can be seen in Hintze et al. (2020, Figure 5A) for stem cell proliferation in C. elegans.

\subsection{PLASTICITY MAY BE ANCESTRALLY ANCESTRAL}

Futuyma (2021) raises the important question of how trait plasticity arises. Most models of the evolution of development postulate that new genotypes are initially sensitive (plastic) to environmental change, with robustness (loss of plasticity) as a subsequent evolutionary feature (Schlichting and Pigliucci 1998; Newman and Müller 2000; Nijhout 2003; Schlichting 2003; Nijhout et al. 2017; Lafuente and Beldade 2019). Evidence for sensitivity of new mutants goes back to the classic work of Dun and Fraser (1959) — who showed that the tabby mutation in mice increased whisker number variability - and is supported by numerous other studies showing that new mutations are relatively uncanalized (Rendel 1967; Baer 2008; Hallgrimsson et al. 2019).

Non-plasticity (i.e., canalization, robustness) is thus arguably a derived state in most biological systems (Nijhout 2003). If plasticity is the ancestral state, then the equally intriguing question for evolutionary biologists is; How does trait stability evolve? Dun and Fraser's (1959) study also showed that variation in whisker number could be decreased via selection (see Hallgrimsson 2019 for further references on 
selection for canalization). There has been a resurgence of interest in how buffering of developmental processes has evolved as evidenced by the plethora of recent reviews on canalization and robustness that document the growing empirical work in this area (Bateson and Gluckman 2011; Félix and Barkoulas 2015; Geiler-Samerotte et al. 2019; Hallgrimsson et al. 2019; Klingenberg 2019; Nijhout et al. 2019). In fact, systems that have evolved genetic and environmental robustness may be more prone to produce truly novel features when these buffering mechanisms, that suppress expression of genetic variants, no longer function (Wagner 2005).

Evolutionarily fine-tuned systems of development (i.e., well buffered against environmental or genetic perturbations) likely arise via functional diversification of duplicate copies of genes. Al Asafen et al. (2020) show that the evolved robustness of dorsal-ventral patterning in the Drosophila embryo requires at least three mechanisms of feedback in the Dorsal signaling module. Ghosh et al. (2019) have shown that selection for increased canalization of development time in Drosophila melanogaster is effective for some environmental perturbations (density) but not for others (temperature). Green et al. (2017) examined robustness by manipulating the dosage of a critical regulator of vertebrate development, the fibroblast growth factor signaling molecule (Fgf8). They found that phenotypic variation in face and skull measurements of mice embryos is not related linearly to the variation in $\mathrm{Fg} f 8$ expression, and that observed differences in levels of robustness among genotypes are predicted by this non-linear 'genotype-phenotype mapping'.

Such buffered systems may subsequently be further altered for cue-specific plasticity, again by deployment of duplicate receptor and signal transduction genes modified to control new plastic responses (Smith 1990; Schlichting and Smith 2002). Ancestral patterns of plastic response may be maintained, modified, or eliminated through processes jointly referred to as 'genetic accommodation' (West-Eberhard 2003). Bhardwaj et al. (2020) have examined the evolution of plasticity in the classic case of seasonal 'polyphenism' of wing eyespots (larger in the warmer dry season) in the butterfly Bicyclus anynana. In Bicyclus, warmer temperatures induce higher production of the hormone $20 \mathrm{E}$ and a corresponding increase in eyespot size. Examining 12 other species of butterfly, Bhardwaj et al. (2020) found that the plasticity of hormone production to temperature is an ancestral feature. However, although receptors for $20 \mathrm{E}$ in the eyespot region are found in several species, only B. anynana shows an increase in eyespot size in response to temperature. Their results suggest that the plastic response of increasing eyespot size results from a modification of the ancestral response via derived genetic changes linking eyespot size and hormone production.

\section{BOX 15.1 TERMS AND DEFINITIONS}

Canalization or robustness. Stability of phenotypes during development following perturbation. Genetic robustness typically refers to the reduction of developmental noise, and environmental robustness refers to the reduction of plasticity. 
Cryptic genetic variation. Genetic variation revealed by environmental or genetic perturbations (Gibson and Dworkin 2004).

Developmental bias. The disproportionally higher production of certain variants following environmental or genetic perturbation (Uller et al. 2018).

Developmental noise. Variation in a phenotype of a trait of a particular genotype under constant environmental conditions.

Ecological developmental biology (eco-devo). The study of how organisms' responses to their environment influence the expression of genetic and developmental programs.

Epigenetic. Originally intended to indicate organism features that arise as a consequence of developmental processes (sensu Waddington; see 'Genotype-phenotype mapping' below); now the term is most often used to refer to whether a particular DNA sequence or histone protein is methylated (an epigenetic mark).

Evolutionary developmental biology (evo-devo). The study of developmental processes in an evolutionary context; e.g., to infer developmental changes leading to phenotypic changes in ancestral-descendant or phylogenetic relationships.

Evolvability. The tendency of a genotype or lineage to generate genetic variability and produce or maintain phenotypic variation over evolutionary time, enabling it to pursue diverse evolutionary trajectories (Schlichting and Murren 2004).

Extended evolutionary synthesis (EES). Driven by a perception that standard evolutionary theory provides an incomplete theoretical scope, the EES proposes to include topics such as evo-devo, evolvability, niche construction, and non-genetic inheritance, and to take into account reciprocal causation (i.e., where identities of causes and effects are fluid; Svensson 2018) and contextdependence (see Müller 2007; Pigliucci 2007; Laland et al. 2015; FábregasTejeda and Vergara-Silva 2018).

Genetic accommodation. A process by which phenotypic variants that are initially strictly environmentally induced are selected to become genetically determined (i.e., heritable) (West-Eberhard 2005; Schlichting and Wund 2014; Ledon-Rettig and Ragsdale 2021). Plasticity may be enhanced or refined (i.e., 'plasticity-led evolution': Levis and Pfennig 2021), or even eliminated (genetic assimilation: Scheiner and Levis 2021).

Genotype-phenotype mapping. Describes the processes that convert the genetic instructions into the visible characteristics of an organism. Explicitly considers effects of gene-gene interactions (pleiotropy and epistasis) and geneenvironment interactions that lead to changes in gene expression. In the case of phenotypic plasticity, there is a one-to-many mapping of a single genotype to the alternate phenotypes possible in different environments.

Hidden reaction norms. Unpredictable extensions of reaction norms in environments outside normally encountered ranges.

Modern synthesis. Stemming from population genetics theory developed by R.A. Fisher, S. Wright, and J.B.S. Haldane, the modern synthesis melded 
concepts of genetics (Mendelian and quantitative) with natural selection to illuminate evolution in natural populations of organisms. The modern synthesis was advanced during the late 1930s and 1940s by T. Dobzhansky, E. Mayr, and others.

Niche construction. The modification of environmental conditions by the actions of an organism; e.g., edifices: beaver dams, burrows, and nests; soil or water alterations: actions of lichens and earthworms, decomposers; allelochemicals of plants.

Non-genetic inheritance. Trait-specific changes to offspring phenotypes induced by parental conditions (Bonduriansky 2021). Also referred to as epigenetic or transgenerational inheritance, and maternal effects (Rossiter 1996).

Phenotypic plasticity. Any change in phenotype by a genotype in response to changes in environmental conditions. A 'reaction norm' is a plot of the response across a set of environments (Sultan 2021).

Polyphenism. The formation of two (or more) distinct phenotypes in response to changes in environmental factors. Classic examples include the castes of social insects, seasonal differences in eyespot size in butterflies, host plant-related larval coloration in caterpillars, and light/dark winter/summer fur or plumage in birds and mammals.

Standard evolutionary theory (SET). The set of generally accepted principles encompassed by the 'modern synthesis' and its post-DNA expansion. Futuyma and Kirkpatrick (2017; Chapter 1: Box 1A) provide a concise listing.

Transcriptome. Whereas a genome records the DNA sequence of an organism revealing its complement of genes, 'transcriptomes' record the expression levels of those genes. They are often used to contrast gene expression levels in different environments, different tissues, or at different life stages (e.g., juvenile versus adult).

\subsection{PLASTICITY AS AN ORIGINATOR OF NOVELTY}

Several authors have pointed out the potential role of plasticity as an originator of new phenotypes for the evolution of behavior (Wcislo 1989; West-Eberhard 1989) and development (Schlichting and Pigliucci 1998; Newman and Müller 2000; Schlichting 2003; West-Eberhard 2003; Schlichting 2008; Gavrilets 2010; Moczek et al. 2011; Wagner et al. 2019). The development of multicellular organisms is itself a continuous set of plastic responses to internally produced stimuli driving changes in gene expression (Sachs 2002). We (Schlichting and Pigliucci 1998; Schlichting 2003) have proposed that multicellularity and differentiation may have arisen through genetic assimilation of sequential plastic responses to changes in internal environments, with novel developmental phenotypes initiated plastically and subsequently canalized so that adaptive developmental sequences are repeatable under broad conditions. In this scenario, the evolution of multicellular development is a recursive process alternating between plasticity (sensitivity of the phenotype to stimuli) and the evolution of robustness (see also Nijhout 2003; Bateson 2017; 
Salazar-Ciudad et al. 2019; Schwab et al. 2019). This is an area of active investigation (Ratcliff et al. 2015; Wolinsky and Libby 2016; Grochau-Wright et al. 2017; Ratcliff et al. 2017; Herron et al. 2018; Herron et al. 2019; Laundon et al. 2019; Rivera-Yoshida et al. 2019; Davison and Michod 2021).

In addition to its potential primal role in multicellular evolution, plasticity has also been implicated in the origin of several major evolutionary features. The social insects, perhaps the most successful group of organisms (Hölldobler and Wilson 2009), owe their success to features that are due to a plastic response: the production of castes and divisions of labor. Berens et al. (2014) compare 'transcriptomes' of fire ants (Solenopsis), honey bees (Apis), and paper wasps (Polistes metricus) to look for commonalities in the plasticity of gene expression across lineages. Although they found little evidence for shared responses at the specific gene level, responses were similar at the level of metabolic pathways, suggesting that these different lineages are employing a shared 'toolkit' for generating convergent plastic responses to nutritional signals (e.g., in the insulin/insulin-like growth signaling pathway, Corona et al. 2016). Sun et al. (2019) investigated transcriptional changes in five castes of the higher termite Macrotermes barneyi, documenting extensive changes between castes in both gene expression and alternative splicing.

Kapheim et al. (2020) have investigated patterns of gene expression in the facultatively eusocial sweat bee Megalopta genalis. This species is an ideal model because females within populations vary in their tendencies towards sociality-some are solitary and others are social. Kapheim et al. designed a comprehensive suite of analyses using an annotated genome, a set of life-stage and sex-specific transcriptomes, and a population genomic comparison of solitary and social females. They discovered very strong associations of genes that have plastic expression during development (i.e., during sexual differentiation and metamorphosis) and genes with expression differences associated with divergence among castes. This suggests that genes with plastic expression patterns were later co-opted/redeployed during the evolution of caste specification. In addition, a broader comparison among species finds that this set of genes shows signs of strong positive selection in many independently derived eusocial insects (Jones and Robinson 2018; Kapheim et al. 2020).

Several research groups have taken advantage of deviations from the canonical insect caste system to examine the origins of plasticity. The ant Diacamma sp. has lost morphological castes, but still has divisions of labor based on social dominance. Okada et al (2017) demonstrated rapid changes in expression levels of genes involved in nutrition (e.g., insulin signaling) that accompany changes in rank. Several studies have focused on the solitary queen species Pogonomyrmex barbatus to examine the plasticity of divisions of labor when social interactions are experimentally imposed and multiple queens are grouped at nest establishment. Fewell and Page (1999) found that phenotypic specialization for nest excavation arose spontaneously in nests populated with multiple queens. Subsequently, Cahan and Gardner-Morse (2013) further showed a nascent division of reproductive labor: although average productivity per queen was maintained, one queen tended to take on a larger fraction of the reproduction.

The nematode genus Pristionchus has delivered several examples of plasticitybased novelty. The best studied is the feeding polyphenism of Pristionchus pacificusindividuals with a narrow 'mouth' and one 'tooth' are bacterivores, and those with a 
wider two-toothed mouth are predators on fungi and other nematodes (Bento et al. 2010). The two-toothed form is induced under low-food conditions, and two genes, the sulfatase gene eud-1 and the sulfotransferase seud-l, have been identified as antagonistic controllers of this plasticity-induced novelty (Ragsdale and Ivers 2016; Namdeo et al. 2018). These genes are both duplicate members of larger gene families that apparently evolved functional specialization to control the mouth polyphenism (Biddle and Ragsdale 2020). Further analyses have identified more details of the regulatory network involved in the switch (Kieninger et al. 2016; Sommer et al. 2017; Sieriebriennikov and Sommer 2018; Bui and Ragsdale 2019): intriguingly loss-offunction eud-1 mutants result in all one-toothed individuals, while loss-of-function $n h r-40$ mutants result in all two-toothed individuals, identifying these as plasticityspecific genes. Susoy et al. (2016) identified three new species of Pristionchus postulated to have feeding polyphenisms; each of these species has five different mouth shape morphologies!

Griffith et al. (2017) present evidence suggesting that the decidua, a distinctive cell layer forming the maternal portion of the placenta in eutherian mammals, arose as a stress response to implantation of the embryo. They demonstrate that features of the attenuated pregnancy of marsupials, such as the inflammation response when the fetal placenta contacts the maternal endometrium, are homologous to events in eutherian pregnancy. The authors propose that this plastic inflammation response is the evolutionary precursor enabling the origin of the anti-inflammatory phase that defines eutherian pregnancy (see also Wagner et al. 2019).

\subsection{GENETIC ACCOMMODATION AND PLASTICITY-LED EVOLUTION}

As mentioned previously, the expansion and refinement of plastic responses represent important evolutionary changes modifying phenotypes of organisms. The general topic of genetic accommodation has been reviewed fairly extensively (Schlichting and Wund 2014; Levis and Pfennig 2017; Schneider and Meyer 2017; Jones and Robinson 2018; Velotta and Cheviron 2018; Kelly 2019), and the specific topic of plasticity-led evolution is covered by Levis and Pfennig (2021), so I will highlight just a few exemplary recent studies.

Plastic responses to low oxygen levels, both short-term (acclimation) and longterm (adaptation), are well-studied, and some short-term changes that accentuate blood flow (hypertrophy of the ventricles) may be maladaptive in the long-term (right ventricular hypertrophy can result in lung disease and heart failure). Velotta et al. (2018) compared two species of deer mice (Peromyscus) that occupy different elevational ranges, comparing heart muscles at normal and reduced oxygen levels (hypoxia). The species had similar right ventricle sizes in normal oxygen levels, but high elevation P. maniculatus had much larger left ventricles. Exposed to low oxygen levels, $P$. maniculatus did not significantly change the size of either ventricle, while the low elevation species $P$. leucopus greatly increased the size of both: under low oxygen $P$. leucopus's left ventricle was about the same size as $P$. maniculatus, but the right ventricle was now $30 \%$ larger than that of $P$. maniculatus. Velotta et al. (2018) suggest that this represents genetic accommodation in $P$. maniculatus via an 
increase in the size of the left ventricle relative to that of $P$. leucopus and a reduction of the plasticity of both ventricles in response to changes in oxygen levels.

The work of Armin Moczek and colleagues on the plasticity of horn size in dung beetles of the genus Onthophagus represents some of the most in-depth examination of the process and mechanisms of genetic accommodation. Males of different species of Onthophagus show varying degrees of nutrition-related plasticity, but in general enhanced nutrition leads to the production of significantly larger horns (Emlen 1994; Moczek 2006). Casasa et al. (2020) examined transcriptomes of adult beetles of three species: Digitonthophagus gazella with a small nutritional response representing the ancestral state; Onthophagus taurus with a derived large nutritional response; and $O$. sagittarius with a derived lack of nutritional response (Emlen et al. 2005). Comparing transcriptomes of orthologous genes across species, Casasa et al. (2020) found only 8 differentially expressed (DE) genes between small and large males of the nutritionally non-responsive $O$. sagittarius, $946 \mathrm{DE}$ genes for the moderately responsive Digitonthophagus gazella, and 1685 DE genes for the highly responsive $O$. taurus, revealing the expected correlation between the plasticity of gene expression and morphological plasticity. Eight hundred and fifty-nine genes that were strongly up-regulated in O. taurus were not differentially expressed in either of the other species, indicating that many genes have evolved increased nutritional sensitivity in the polyphenic $O$. taurus. The gene expression evidence also indicates that the secondary loss of plasticity in $O$. sagittarius results from the loss of nutritional sensitivity of many genes. These results indicate widespread genetic accommodation of plastic responses, both to enhance and reduce plasticity in different species. Evidence for evolutionary changes in plasticity have also been documented among different populations of $O$. taurus (Moczek et al. 2002; Rohner and Moczek 2020).

Corl et al. (2018) examined color dimorphism among populations of side-blotched lizards (Uta stansburiana) occupying different substrates in southern California. Populations of typical gray and tan mottled lizards from sandy substrates and dark lizards from the Pisgah lava flow (22,500 years ago; Figure 15.2a) were established in the laboratory on both lava rock and sand. Skin reflectance was measured after 1 year for each of the four groups: sand-sand (Figure 15.2b), lava-lava (Figure 15.2c), lava-sand (Figure 15.2d), and sand-lava. Lizards from both sand and lava substrates exhibited substantial phenotypic plasticity in coloration: both groups that were switched adopted coloration more similar to the new substrate (Figure 15.2e). Lizards from the lava flow were significantly darker on both substrates, and Corl et al. identified genetic differences between the sand and lava populations. Allele frequencies of two candidate genes regulating melanin production were found to differ strongly between populations: sand populations were monomorphic for the ancestral allele, but the lava population had derived alleles at each locus with frequencies $>20 \%$. Hatchling lizards carrying the derived alleles were darker. The combined results imply a scenario where plasticity present in the initial population provided an adaptive advantage to lizards living on the new lava substrate; subsequently, new alleles arose that increased the constitutive darkness of lava lizards - demographic simulations suggest that these alleles arose about 1000 generations ago and both are under positive selection (Corl et al. 2018). 

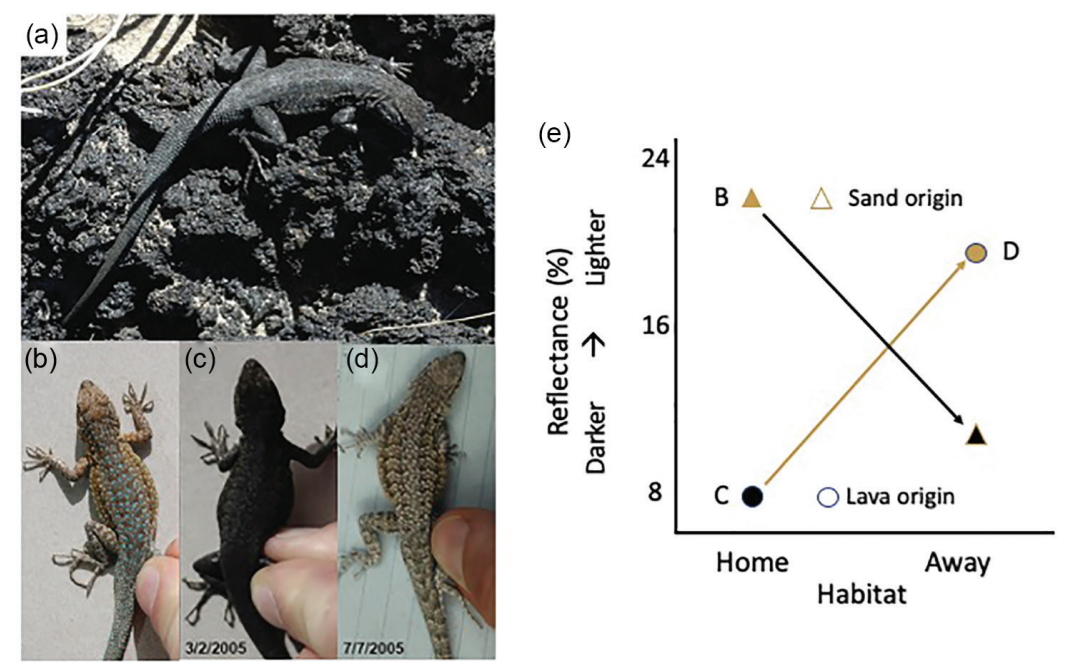

FIGURE 15.2 (a) The side-blotched lizard Uta stansburiana on lava rock. Individuals were collected from populations on sand and lava rock substrates. In the lab, they were placed in habitats with either sand or lava gravel. After 1 year, their reflectance was measured. (b) Sand origin after 1 year on sand. (c) Lava origin after 1 year on lava. (d) The same Lava origin lizard after 4 months on sand. (e) Lizards switched both from sand to lava and lava to sand responded plastically to produce coloration more similar to the resident populations. (Panels [a], [c], and [d] are reprinted from Current Biology 28:18, Corl et al., The genetic basis of adaptation following plastic changes in coloration in a novel environment, pp. 2970-2977, Copyright [2018], with permission from Elsevier; [b] courtesy of Ammon Corl.)

\subsection{PLASTICITY AND SPECIES DIVERGENCE}

Plastic responses to environmental variation may initiate reproductive isolation between adjacent populations. This isolation can take various forms-via alterations of phenology (Rajakaruna et al. 2003; Buckley et al. 2015; Dittmar and Schemske 2017; Taylor and Friesen 2017; Osborne et al. 2019), diet or host (Smith et al. 2013; Moser et al. 2015; Silva-Brandão et al. 2017), signaling (Iglesias et al. 2018; Otte et al. 2018), or even morphology (Garduno-Paz et al. 2020). Schlichting (2004), West-Eberhard (2005), and Pfennig et al. (2010) reviewed many examples, and subsequent authors have elaborated (Levin 2009; Fitzpatrick 2012; Schneider and Meyer 2017; Otte et al. 2018).

Treehoppers (Homoptera: Membracidae) of the Enchenopa binotata species complex are remarkable for host-plant associated speciation across a broad diversity of host trees (from eight different plant orders). Enchenopa communicate via vibrational signals through the substrate (i.e., stems, leaves, and petioles), and the comparison of signals of males from 11 Enchenopa species (each from a different tree species) revealed extensive differentiation in all measured aspects of the signals (e.g., frequency, amplitude, and duration; Cocroft et al. 2010). The key driver of speciation appears to be the species' philopatry-females show strong preferences for laying their eggs on the tree species upon which they developed (Wood and Guttman 1982; 
Stearns et al. 2013). However, signal propagation changes plastically on different plant species (Sattman and Cocroft 2003; McNett and Cocroft 2008), and Rodriguez et al. (2008) have shown not only differences in signaling of individuals on different host species, but also genetic variation in signaling on a novel host-i.e., the raw material for precipitating genetic changes.

Etges and colleagues have studied populations of the cactophilic Drosophila mojavensis from Baja California (ancestral) and Sonora (derived) adapted to different cactus species, Stenocereus gummosus (pitaya agria) and S. thurberi (organ pipe), respectively (Etges et al. 2010). Cuticular hydrocarbons (CHCs) are important pheromones involved in sexual discrimination among males by females, and the differences in CHC mixtures between Baja and Sonora populations are important for premating isolation between them (Etges and Ahrens 2001). Although growth on the different cactus species significantly alters CHC profiles of flies (Stennett and Etges 1997; Etges and de Oliveira 2014), a direct link between plastic changes in CHC composition and mating preferences has not been made.

Sorenson et al. (2003) documented a remarkable example of behavioral plasticity initiating components of an adaptive radiation of 19 bird species (the indigobirds, genus Vidua) as brood parasites on grassfinches (Estrildidae). Rapid speciation is possible because Vidua species acquire mating traits through imprinting on their hosts-i.e., males learn their songs from their foster parent male and females adopt preferences both for those songs and for nests of the host species. This system has recently been revisited by Jamie et al. (2020), who find that additional components of the parasitic Vidua's phenotypes also mimic those of the host species, enhancing reproductive isolation among Vidua species. They document several putative adaptations: mimicry of nestling behavior (matching of the presence/absence of head rotation or tongue movement while begging), mimicry of the parasites' calls to those of the host species (rather than to calls of other local grassfinch species), and mimicry of hatchling mouth coloration used as signals to parents while begging (more similar to markings of host than to markings of other local grassfinch species). Such further adaptations become more likely following reproductive isolation established by the initial plastic imprinting.

Garduno-Paz et al. (2020) started with a single population of stickleback and then induced plastic benthic (shoreline) and pelagic (open-water) feeding morphologies via diet modifications. Body morphology after 10 months on each diet showed the typical differences - benthic fish with comparatively shorter heads and jaw bones and deeper bodies (each fish was given a multivariate pelagic-benthic score based on morphology relative to a benthic-pelagic continuum). 'Benthic' and 'pelagic' experimental females were then simultaneously shown size-matched mates of each morphology group. Pelagic females were significantly more likely to mate with males that were similar in their shape score, i.e., males with similar morphology. They note that coupling the sharing of feeding locations with mating preference for similar shapes could make this plastic response a 'magic' trait-i.e., a simultaneous change in the morphology and a preference for it.

Plasticity may also play an important role in character displacement with plastic responses increasing differences between sympatric populations of species (Pfennig and Pfennig 2012; Robinson and Pfennig 2013 specifically examine the case for 
character displacement following competition). An example of character displacement by means of the evolution of plastic responses is seen in the competing toad species Spea bombifrons and S. multiplicata (Pfennig et al. 2007). Both species are detritivores that can plastically produce a carnivorous tadpole morph when shrimp are presentthis morph is larger, with larger jaws and a shorter gut. Remarkably, in sympatry with $S$. multiplicata, S. bombifrons does not produce the detritivore morph. Levis et al. (2017) pinpoint some of the genetic correlates of the loss of plasticity, identifying two genes in particular that show patterns of expression that differ between diets (detritus versus shrimp) and $S$. bombifrons populations (sympatric with $S$. multiplicata versus allopatric). The protein-coding peptidase gene Pm20d2 had higher expression in the shrimp diet, but relatively reduced expression in $S$. bombifrons populations sympatric with $S$. multiplicata. The transcription factor Btf3 also has higher expression in the shrimp diet, but only in allopatric $S$. bombifrons; gene expression plasticity has been lost in sympatric populations. Thus, these two genes show the evolution of expression patterns; their particular functions in morph production are yet unknown.

\subsection{PLASTICITY PRODUCES DISTINCTIVE EVOLUTIONARY DYNAMICS}

One significant consequence of plasticity for evolutionary dynamics was pointed out by Sewall Wright_-plasticity can hide genetic variation (Wright 1931). A plastic response can move organisms to a different adaptive peak, even if allelic variation is available that might otherwise facilitate adaptive evolution. If the new environment is stable, we then have adaptation via plasticity but evolutionary stasis, a fundamentally different dynamic than adaptive evolution by allelic substitution.

Another fundamental role of plasticity in altering evolutionary dynamics arises from the changes in gene expression that altered environmental conditions produce (see Goldstein and Ehrenreich 2021 in this volume). Numerous studies have demonstrated that the genetic architecture (i.e., pleiotropy, epistasis, and genetic correlations) of a population may itself be strongly modified by the environment (Draghi and Whitlock 2012; Wood and Brodie III 2015; Parsons et al. 2016; Rowinski and Rogell 2017; Gibert et al. 2019; Schou et al. 2019). Thus, if one were to raise genetically identical populations in alternate environments (e.g., different temperatures, water availability, $\mathrm{pH}$, and predators), their divergent genetic architectures can cause them to exhibit distinctive evolutionary responses to subsequent evolutionary challenges (e.g., herbivory, predation; Schlichting 1989).

Pespeni et al. (2017) found that, in Onthophagus beetles, genes that are conditionally expressed, i.e., only in specific environments, showed much stronger signals of previous natural selection. This pattern is predicted because selection on such alleles is relaxed in non-eliciting environments (Snell-Rood et al. 2010). Along these lines, a meta-analysis by Noble et al. (2019) indicated that the directions of plastic responses to novel environments are aligned with those aspects of the phenotype that also have significant heritability, suggesting that integrated phenotypes respond similarly to genetic and environmental perturbations.

Thus, the dynamics of both population genetic and quantitative genetic models can be altered by plastic responses or forms of 'non-genetic inheritance' (changes to 
offspring phenotypes induced by parental environmental conditions; Danchin et al. 2011; Bonduriansky 2021). Early models demonstrated that non-genetic modes of inheritance can significantly alter the evolutionary dynamics of populations relative to predictions of standard genetic models (Hinton and Nowlan 1987; Laland et al. 1999). These have been augmented by more general models incorporating plasticity or non-genetic inheritance (Bonduriansky and Day 2009; Day and Bonduriansky 2011; Frank 2011a,b; Klironomos et al. 2013; Bonduriansky and Day 2018), showing lags, accelerations, bumps, and plateaus in evolutionary change.

Recent models have extended findings for plasticity. Coulson et al. (2017) develop a series of integral projection models that incorporate development (i.e., genotypephenotype mapping) and mechanisms of inheritance, and contrasted how different instantiations of phenotypic plasticity (e.g., no phenotypic plasticity, adaptive phenotypic plasticity, and non-adaptive phenotypic plasticity) can influence evolutionary responses to environmental change. Populations with adaptive plasticity, despite suffering initial declines, show the most rapid rate of adaptive evolution to new environments. Their models also suggest that some reported examples of rapid evolution are more likely to be due to initial plastic responses than to genetic evolution.

Jeremy Draghi has developed models that examine the interplay of developmental noise and plasticity. Draghi (2019) examined a model in which developmental noise is controlled by the genotype and thus can evolve. In this model, low developmental noise (i.e., canalization) is favored in constant environments but tends to impede further evolution of plasticity via the reduction in phenotypic variability. This is particularly true when the suppression of developmental noise arises through negative feedbacks (e.g., antagonistic pleiotropic effects of different genes). However, replicates that evolved canalization without pleiotropy were not as constrained, indicating that how variability is controlled will influence the evolution of the system. Draghi (2020) took a different approach, allowing developmental noise to be induced by the environment, but the results are similar in that plasticity is again more likely to evolve when environmental noise is higher because the developmental noise creates more phenotypic variability and thus more opportunities to achieve phenotypes that increase fitness.

Several recent studies have also experimentally evaluated the effects of nongenetic inheritance. Dey et al. (2016) found that C. elegans subjected to predictable (alternating) normal versus low oxygen environments evolved plastic anticipatory maternal effects, such that mothers increased or decreased glycogen provisioning 'anticipating' next-generation conditions. They modeled evolution in predictably fluctuating versus randomly fluctuating environments and found that populations that evolved anticipatory maternal effects had increased adaptability (i.e., higher fitnesses) in subsequent random environmental sequences. Samani and Bell (2016) experimentally examined the dynamics of evolutionary rescue of wild yeast populations (Saccharomyces paradoxus) in relation to their prior evolutionary histories. They first selected lines for 4 weeks on fructose (non-stressful) and 11 other sugars that reduced population growth rates (starvation-adapted), then subjected all lines to four novel environmental factors: high temperature, high $\mathrm{pH}$, alcohol, and salt. Intriguingly, the starvation-adapted lines had reduced adaptive plasticity relative to the fructose lines, but a higher subsequent likelihood of adapting to the novel 
challenges: the more versatile fructose lines did not adapt to any of the novel challenges. Their results suggest that initial favorable plasticity actually inhibited subsequent evolutionary rescue. The diverse results of such experimental and model studies are fueling new hypotheses about how plasticity can evolve in heterogeneous environments (Bono et al. 2020).

\subsection{PLASTICITY AND EVOLUTIONARY THEORY}

The core structure of the modern synthesis, population genetics, is a rigorous and successful set of models of how evolutionary forces can alter allele frequencies. Likewise, quantitative genetics is a proven model for projecting statistical changes in distributions of polygenic traits over spans of a few generations. Neither population genetics nor quantitative genetics, however, inform us about how phenotypes are produced, how development proceeds, or how environment alters gene expression (Gawne et al. 2018; Hallgrimsson et al. 2019). Because selection operates on phenotypes, and only indirectly on the alleles that produce them, it is of paramount importance to understand mechanisms by which variation in phenotypes arises and increases, whether these variants are behavioral, physiological, or developmental. Phenotypes result from 'epigenetic' processes (in the Waddingtonian sense) that act to produce developmental trajectories (Schmalhausen 1949; Waddington 1953). Traits of organisms and their responses to variation in local environments (both external and internal) are central to understanding how evolutionary processes of selection and drift impact trajectories of phenotypic evolution.

To answer questions about phenotypes and traits, we need disciplines including 'evolutionary developmental biology' (evo devo), 'ecological developmental biology' (eco devo; Sultan 2015), and molecular ecology and genetics to investigate phenomena such as 'cryptic genetic variation' (Gibson and Dworkin 2004; LedónRettig et al. 2014; Zheng et al. 2019), 'evolvability' (Wagner and Altenberg 1996; Schlichting and Murren 2004; Payne and Wagner 2019), canalization and robustness (Flatt 2005; Nijhout et al. 2019), 'developmental bias' (Uller et al. 2018), 'niche construction' (Laland et al. 2019), non-genetic inheritance (Danchin et al. 2011), and of course phenotypic plasticity. These fields and topics represent a broad research initiative focused on understanding the processes and mechanisms underlying the production, evolution, and importance of phenotypic diversity (e.g., Rollo 1994; Schlichting and Pigliucci 1998; West-Eberhard 2003; Pfennig et al. 2010; Bolnick et al. 2011; Moczek et al. 2011; Laland et al. 2015; Sultan 2015, 2017; van Gestel and Weissing 2016; Peichel and Marques 2017; Des Roches et al. 2018; Duclos et al. 2019; Glastad et al. 2019; Müller 2019; Herrel et al. 2020).

In this essay, I have highlighted evidence that plasticity occupies a conceptual nexus with links throughout evolutionary biology, impacting all hierarchical levels of evolution-macroevolution (origin of novelties), mesoevolution (speciation), and microevolution (adaptation). As Futuyma (2021) points out, plasticity has been identified as a key concept in an array of topics that some authors have suggested raise questions for evolutionary theory, and thus merit an 'extended evolutionary synthesis' (EES; Müller 2007; Pigliucci 2007). The ensuing arguments and counterarguments between proponents of EES and 'standard evolutionary theory' (SET) have been 
predictably bloody in the academic fashion, with defenders of SET asserting that it can easily encompass all these topics (Laland et al. 1999; Wray et al. 2014).

The philosophy of biology community has welcomed the controversy between the EES and SET camps as a testing ground for ideas about research programs and paradigm shifts (Fábregas-Tejeda and Vergara-Silva 2018; Lewens 2019), and as with the debates among evolutionists, there are a diversity of opinions. In both fields, many arguments revolve around 'virtue-based' disputes (Buskell 2020): are plasticity's effects 'likely' enough, or 'significant' or 'strong' enough (Kovaka 2019; Baedke et al. 2020). Such arguments are ultimately obfuscatory, calling for decisions about whether some arbitrarily defined hurdle has been surmounted.

Rather than focusing on polarizing differences of opinion, it is probably most interesting for our purposes to be curious about these external views for their prescriptions on strategies for informing the debate. Baedke et al. (2020) call for an approach based on 'explanatory' power and applying explanatory standards (precision, proportionality, sensitivity, and idealization): "explanatory power can be assessed by comparing the range of inferences to potentially new counterfactual situations and, accordingly, of answers to w-questions ['what-if-things-had-beendifferent'] that alternative explanations make possible. For example, an explanation of a particular population dynamic that includes developmental factors might be able to answer more questions on what would happen to this population if it was changed" (Baedke et al. 2020 pp. 7-8, see also Uller et al. 2020).

Kovaka (2019) advocates a related approach, employing evidentiary standards of 'discrimination' and 'significance-relevant.' She suggests that, at least for the debate about plasticity-led evolution, "researchers need a richer middle-range theory" (i.e., one describing the relationship between plasticity-led evolution and observable evidence). This middle-range should be focused on evidentiary support to identify the 'traces' that characterize plasticity-led evolution. Kovaka proposes that, although direct evidence from natural populations is important, identifying signatures of plasticity-led evolution that distinguish it from SET models may be accomplished via, for example, experimental evolution, genomic comparisons, and modeling of plasticity-led versus genotype-led evolutionary dynamics.

Uller et al. (2020) propose that it may be the representation of plasticity itself as a reaction norm that is creating a block to appreciating its 'transformational' role in evolution. Because reaction norms have been conceptualized as manifestations of specific genotypes, they can easily be binned as yet another example of genetic variation to be collapsed into relative fitnesses on which selection may operate. Uller et al. (2020) argue that it is this "genetic idealization of evolution by natural selection" that allows unique details of development, physiology, or behavior to be ignored because they are unnecessary to explain a pattern of evolutionary change. They suggest that adopting alternative idealizations of evolutionary dynamics may produce more satisfactory explanations of patterns of phenotypic evolution.

\subsection{WHERE SHOULD WE BE GOING?}

As documented in this chapter and volume, phenotypic plasticity has multifarious connections with evolutionary biology and can have striking non-canonical effects 
on evolutionary processes and their outcomes. I have previously avoided joining the arguments about EES versus SET, expecting that, after the initial volleys, both sides would continue profitable work in their specialties, with eventual rapprochement. However, I have become frustrated as defenders of the omniscient nature of SET continually expand the list of concepts that it can accommodate-such claims appear increasingly Procrustean. There are areas of evolutionary biology on which the SET is silent - the origin of novelties; biases in mutation or development; evolvability; evolution of the genotype to phenotype map; and the unfolding of development. Should we be content leaving these issues to the side, settling for a theory that seems adequate, or do we want to build theories with increased explanatory power?

The SET is in no danger of being eclipsed-it is still clearly fundamental for understanding the evolution of populations subject to selection and drift, but it just as clearly is not an encompassing theory of evolutionary processes. Futuyma (2021) argues that understanding the evolutionary importance of plasticity and related concepts just requires details of "the effects of mutation, gene flow, genetic drift, and especially natural selection on the frequencies of alleles and genotypes, ... it's still genes and selection, all the way down." I counter that this distinctly gene-centric view of evolution, with its explicit perspective of phenotypes as byproducts, is myopic. The standard view of a genotype mapping to a single phenotype with a particular fitness is misleading at best, and likely inaccurate for most genes: via plasticity, a single genotype can produce multiple phenotypes, and each of those phenotypes will have its own environment-dependent fitness.

I propose that a view of evolution as a recursive process involving both the generation and sorting of variation is a more accurate and flexible perspective. Many of the topics embraced by supporters of an EES are related to the generation of variation. The SET, on the other hand, encompasses a wealth of theory about the sorting of variation. A full view sees new phenotypes produced via new mutation or exposure to new 'environments' (including new genetic backgrounds, new developmental milieus, and new external conditions), followed by processes that sort such variation-selection, drift, and gene flow (see e.g. Fábregas-Tejeda and Vergara-Silva 2018).

Thus, new empirical and modeling efforts to identify the roles of plasticity in evolution must explicitly recognize the complementarity of the processes involved in generating and sorting variation. Advances are already being made to construct more realistic models of evolution that incorporate separate terms for both genetic and environmental components of phenotypic variation. Such models can incorporate either of the benchmark equations of trait evolution (Breeder's or Price's equations) into population dynamic models for forecasting evolutionary trajectories (Coulson et al. 2020; Helanterä and Uller 2020; Rice 2020).

There are many avenues to explore on our way to a more complete understanding of how plasticity evolves. This will require building upon the recent surge of excellent work in ecological and evolutionary developmental biology and molecular ecology and genetics to get a clear picture of the genes and signal transduction pathways that control plastic responses. A better phylogenetic understanding of patterns and processes of the evolution of variation in plasticity is also needed. Results from work in these areas can then be viewed through the lens of robust models of evolution in populations that account for both genetic and environmental sources of phenotypic variation. Box 15.2 lists some suggestions for future research. 


\section{BOX 15.2 SUGGESTIONS FOR FUTURE RESEARCH}

- Cryptic genetic variation and hidden reaction norms. Theory suggests that novel or rarely encountered environments should reveal cryptic genetic variation. This is an empirical question that can be addressed with experiments that expose organisms to a range of environments that span normal and unusual conditions.

- Plasticity in a phylogenetic context. Despite well-developed theory about when plasticity should evolve, most evidence of evolutionary change consists of comparisons of pairs of species or populations (Murren et al. 2014). There are actually very few mappings of divergence in plastic responses across phylogenies (Relyea et al. 2018). These should be produced via controlled environment studies examining responses of a group of species (e.g., congeneric taxa) to a set of environmental conditions. Such studies can answer questions about magnitude, direction, and rate of evolutionary change of plastic responses.

- Distinguishing adaptive from non- or maladaptive plasticity is experimentally difficult due to both the lack of appropriate genetic variants (highly adaptive plastic responses are likely to be fixed) and the scope of experimental designs. We need to employ the power of genomic and transcriptomic studies to uncover signatures of selection on genes and pathways related to plastic responses.

- Integration of plastic responses of phenotypes. How are plastic responses of different traits coordinated? (Schlichting 1989). There have been investigations examining pieces of this puzzle from the trait side (e.g., Buehler et al. 2012; Michimae and Emura 2012; Ellers and Liefting 2015; Rusman et al. 2018; Wright et al. 2018; Parsons et al. 2020) and many studies from the gene expression side (e.g., Mäkinen et al. 2017; Mark et al. 2019). Although examples are beginning to accumulate that link trait values and gene expression patterns (e.g., Casasa et al. 2020; Jacobs et al. 2020), there is a need for coordination of the concepts and literatures on the integration of trait plasticities and plasticity/modularity of gene expression.

- Following from Kovaka's (2019) prescriptions for detecting evolutionary signatures:

- Contrast evolutionary dynamics of plastic versus non-plastic lineages in selection experiments. Such experiments could contrast outcomes for the evolution of plasticity from (1) experiments that select for a new trait mean versus (2) experiments that select on the plastic responses themselves. Both real and in silico populations could be followed (see e.g. Sikkink et al. 2019).

- Examine the evolution of patterns of gene expression (transcriptomics) among recently diverged populations to discover characteristic patterns of change related to the evolution of plasticity (see discussion of work by Pfennig and colleagues above). 


\section{ACKNOWLEDGMENTS}

Thanks to Doug Futuyma, David Pfennig, and an anonymous reviewer for their cogent comments on a draft of this chapter. Their observations and requests for clarity have made this a much better piece.

\section{REFERENCES}

Al Asafen, H., P. U. Bandodkar, S. Carrell-Noel, A. E. Schloop, J. Friedman, and G. T. Reeves. 2020. Robustness of the Dorsal morphogen gradient with respect to morphogen dosage. PLoS Computational Biology 16:e1007750.

Baedke, J., A. Fábregas-Tejeda, and F. Vergara-Silva. 2020. Does the extended evolutionary synthesis entail extended explanatory power? Biology and Philosophy 35:20.

Baer, C. F. 2008. Quantifying the decanalizing effects of spontaneous mutations in rhabditid nematodes. American Naturalist 172:272-281.

Bateson, P. 2017. Robustness and plasticity in development. WIREs Cognitive Science 8:e1386.

Bateson, P. and P. Gluckman. 2011. Plasticity, Robustness, Development and Evolution. Cambridge University Press, Cambridge.

Bento, G., A. Ogawa, and R. J. Sommer. 2010. Co-option of the hormone-signalling module dafachronic acid-DAF-12 in nematode evolution. Nature 466:494-497.

Berens, A. J., J. H. Hunt, and A. L. Toth. 2014. Comparative transcriptomics of convergent evolution: Different genes but conserved pathways underlie caste phenotypes across lineages of eusocial insects. Molecular Biology and Evolution 32:690-703.

Bhardwaj, S., L. Jolander, S-H., M. R. Wenk, J. C. Oliver, H. F. Nijhout, and A. Monteiro. 2020. Origin of the mechanism of phenotypic plasticity in satyrid butterfly eyespots. eLife 9:e49544.

Biddle, J. F. and E. J. Ragsdale. 2020. Regulators of an ancient polyphenism evolved through episodic protein divergence and parallel gene radiations. Proceedings of the Royal Society B: Biological Sciences 287:20192595.

Bolnick, D. I., P. Amarasekare, M. S. Araujo, R. Burger, J. M. Levine, M. Novak, V. H. W. Rudolf, S. J. Schreiber, M. C. Urban, and D. A. Vasseur. 2011. Why intraspecific trait variation matters in community ecology. Trends in Ecology \& Evolution 26:183-192.

Bonduriansky, R. 2021. Plasticity across generations. In D. W. Pfennig, ed., Phenotypic Plasticity and Evolution: Causes, Consequences, Controversies. CRC Press, Boca Raton, FL.

Bonduriansky, R. and T. Day. 2009. Nongenetic inheritance and its evolutionary implications. Annual Review of Ecology Evolution and Systematics 40:103-125.

Bonduriansky, R. and T. Day. 2018. Extended Heredity: A New Understanding of Inheritance and Evolution. Princeton University Press, Princeton NJ.

Bono, L. M., J. A. Draghi, and P. E. Turner. 2020. Evolvability costs of niche expansion. Trends in Genetics 36:14-23.

Buckley, L. B., C. R. Nufio, E. M. Kirk, and J. G. Kingsolver. 2015. Elevational differences in developmental plasticity determine phenological responses of grasshoppers to recent climate warming. Proceedings of the Royal Society B: Biological Sciences 282:20150441.

Buehler, D. M., F. Vezina, W. Goymann, I. Schwabl, M. Versteegh, B. I. Tieleman, and T. Piersma. 2012. Independence among physiological traits suggests flexibility in the face of ecological demands on phenotypes. Journal of Evolutionary Biology 25:1600-1613.

Bui, L. T. and E. J. Ragsdale. 2019. Multiple plasticity regulators reveal targets specifying an induced predatory form in nematodes. Molecular Biology and Evolution 36:2387-2399. 
Buskell, A. 2020. Synthesising arguments and the extended evolutionary synthesis. Studies in History and Philosophy of Science Part C: Studies in History and Philosophy of Biological and Biomedical Sciences 80:101244.

Cahan, S. H. and E. Gardner-Morse. 2013. The emergence of reproductive division of labor in forced queen groups of the ant Pogonomyrmex barbatus. Journal of Zoology 291:12-22.

Casasa, S., E. E. Zattara, and A. P. Moczek. 2020. Nutrition-responsive gene expression and the developmental evolution of insect polyphenism. Nature Ecology \& Evolution 4:970-978.

Clausen, J., D. D. Keck, and W. M. Hiesey. 1940. Experimental studies on the nature of species. I. Effect of varied environment on western North American plants. Publication 520, Carnegie Institution of Washington, Washington, DC.

Cocroft, R. B., R. L. Rodriguez, and R. E. Hunt. 2010. Host shifts and signal divergence: Mating signals covary with host use in a complex of specialized plant-feeding insects. Biological Journal of the Linnean Society 99:60-72.

Corl, A., K. Bi, C. Luke, A. S. Challa, A. J. Stern, B. Sinervo, and R. Nielsen. 2018. The genetic basis of adaptation following plastic changes in coloration in a novel environment. Current Biology 28:2970-2977.

Corona, M., R. Libbrecht, and D. E. Wheeler. 2016. Molecular mechanisms of phenotypic plasticity in social insects. Current Opinion in Insect Science 13:55-60.

Coulson, T., B. E. Kendall, J. Barthold, F. Plard, S. Schindler, A. Ozgul, and J.-M. Gaillard. 2017. Modeling adaptive and nonadaptive responses of populations to environmental change. American Naturalist 190:313-336.

Coulson, T., T. Potter, and A. Felmy. 2020. Dynamic Price and Breeder's equations for variable environments. bioRxiv:762658.

Danchin, É., A. Charmantier, F. A. Champagne, A. Mesoudi, B. Pujol, and S. Blanchet. 2011. Beyond DNA: Integrating inclusive inheritance into an extended theory of evolution. Nature Reviews Genetics 12:475-486.

Davison, D. R. and R. E. Michod. 2021. Phenotypic plasticity and evolutionary transitions in individuality. In D. W. Pfennig, ed. Phenotypic Plasticity and Evolution: Causes, Consequences, Controversies. CRC Press, Boca Raton, FL.

Day, T. and R. Bonduriansky. 2011. A unified approach to the evolutionary consequences of genetic and nongenetic inheritance. American Naturalist 178:E18-E36.

Des Roches, S., D. M. Post, N. E. Turley, J. K. Bailey, A. P. Hendry, M. T. Kinnison, J. A. Schweitzer, and E. P. Palkovacs. 2018. The ecological importance of intraspecific variation. Nature Ecology \& Evolution 2:57-64.

Dey, S., S. R. Proulx, and H. Teotónio. 2016. Adaptation to temporally fluctuating environments by the evolution of maternal effects. PLoS Biology 14:e1002388.

Dittmar, E. and D. W. Schemske. 2017. The edaphic environment mediates flowering-time differentiation between adjacent populations of Leptosiphon parviflorus. Journal of Heredity 109:90-99.

Donnelly, K., S. Cavers, J. E. Cottrell, and R. A. Ennos. 2018. Cryptic genetic variation and adaptation to waterlogging in Caledonian Scots pine, Pinus sylvestris L. Ecology and Evolution 8:8665-8675.

Draghi, J. 2019. Phenotypic variability can promote the evolution of adaptive plasticity by reducing the stringency of natural selection. Journal of Evolutionary Biology 32:1274-1289.

Draghi, J. 2020. Developmental noise and ecological opportunity across space can release constraints on the evolution of plasticity. Evolution \& Development 22:35-46.

Draghi, J. A. and M. C. Whitlock. 2012. Phenotypic plasticity facilitates mutational variance, genetic variance, and evolvability along the major axis of environmental variation. Evolution 66:2891-2902. 
Duclos, K. K., J. L. Hendrikse, and H. A. Jamniczky. 2019. Investigating the evolution and development of biological complexity under the framework of epigenetics. Evolution \& Development 2019:e12301.

Dun, R. B. and A. S. Fraser. 1959. Selection for an invariant character, vibrissa number, in the house mouse. Australian Journal of the Biological Sciences 12:506-523.

Ellers, J. and M. Liefting. 2015. Extending the integrated phenotype: covariance and correlation in plasticity of behavioural traits. Current Opinion in Insect Science 9:31-35.

Emlen, D. J. 1994. Environmental control of horn length dimorphism in the beetle Onthophagus acuminatus (Coleoptera: Scarabaeidae). Proceedings of the Royal Society of London B-Biological Sciences 256:131-136.

Emlen, D. J., J. Hunt, and L. W. Simmons. 2005. Evolution of sexual dimorphism and male dimorphism in the expression of beetle horns: Phylogenetic evidence for modularity, evolutionary lability, and constraint. American Naturalist 166:S42-S68.

Etges, W. J. and M. A. Ahrens. 2001. Premating isolation is determined by larval-rearing substrates in cactophilic Drosophila mojavensis. V. Deep geographic variation in epicuticular hydrocarbons among isolated populations. The American Naturalist 158:585-598.

Etges, W. J. and C. C. de Oliveira. 2014. Premating isolation is determined by larval rearing substrates in cactophilic Drosophila mojavensis. X. Age-specific dynamics of adult epicuticular hydrocarbon expression in response to different host plants. Ecology and Evolution 4:2033-2045.

Etges, W. J., C. C. De Oliveira, M. A. F. Noor, and M. G. Ritchie. 2010. Genetics of incipient speciation in Drosophila mojavensis. III. Life-history divergence in allopatry and reproductive isolation. Evolution 64:3549-3569.

Fábregas-Tejeda, A. and F. Vergara-Silva. 2018. The emerging structure of the extended evolutionary synthesis: Where does Evo-Devo fit in? Theory in Biosciences 137:169-184.

Félix, M.-A. and M. Barkoulas. 2015. Pervasive robustness in biological systems. Nature Reviews Genetics 16:483-496.

Fewell, J. H. and R. E. Page Jr. 1999. The emergence of division of labour in forced associations of normally solitary ant queens. Evolutionary Ecology Research 1:537-548.

Fitzpatrick, B. M. 2012. Underappreciated consequences of phenotypic plasticity for ecological speciation. International Journal of Ecology 2012:256017.

Flatt, T. 2005. The evolutionary genetics of canalization. Quarterly Review of Biology 80:287-316.

Frank, S. A. 2011a. Natural selection. I. Variable environments and uncertain returns on investment. Journal of Evolutionary Biology 24:2299-2309.

Frank, S. A. 2011b. Natural selection. II. Developmental variability and evolutionary rate. Journal of Evolutionary Biology 24:2310-2320.

Futuyma, D. J. 2021. How does phenotypic plasticity fit into evolutionary theory? In D. W. Pfennig, ed., Phenotypic Plasticity and Evolution: Causes, Consequences, Controversies. CRC Press, Boca Raton, FL.

Futuyma, D. J. and M. Kirkpatrick. 2017. Evolution. Sinauer Associates, Sunderland, MA.

Garduno-Paz, M. V., F. A. Huntingford, S. Garrett, and C. E. Adams. 2020. A phenotypically plastic magic trait promoting reproductive isolation in sticklebacks? Evolutionary Ecology 34:123-131.

Gavrilets, S. 2010. Rapid transition towards the division of labor via evolution of developmental plasticity. PLoS Computational Biology 6:e1000805.

Gawne, R., K. Z. McKenna, and H. F. Nijhout. 2018. Unmodern synthesis: Developmental hierarchies and the origin of phenotypes. BioEssays 40:1600265.

Geiler-Samerotte, K., F. M. O. Sartori, and M. L. Siegal. 2019. Decanalizing thinking on genetic canalization. Seminars in Cell \& Developmental Biology 88:54-66.

Ghalambor, C. K., J. K. McKay, S. P. Carroll, and D. N. Reznick. 2007. Adaptive versus nonadaptive phenotypic plasticity and the potential for contemporary adaptation in new environments. Functional Ecology 21:394-407. 
Ghosh, S. M., K. M. Satish, M. Jayaram, and A. Joshi. 2019. Does long-term selection for development time result in canalization: A test using Drosophila melanogaster. Frontiers in Ecology and Evolution 7:228.

Gibert, P., V. Debat, and C. K. Ghalambor. 2019. Phenotypic plasticity, global change, and the speed of adaptive evolution. Current Opinion in Insect Science 35:34-40.

Gibson, G. and I. Dworkin. 2004. Uncovering cryptic genetic variation. Nature Reviews Genetics 5:681-690.

Glastad, K. M., B. G. Hunt, and M. A. D. Goodisman. 2019. Epigenetics in insects: Genome regulation and the generation of phenotypic diversity. Annual Review of Entomology 64:185-203.

Goldstein, I. and I. M. Ehrenreich. 2021. Genetic variation in phenotypic plasticity. In D. W. Pfennig, ed., Phenotypic Plasticity and Evolution: Causes, Consequences, Controversies. CRC Press, Boca Raton, FL.

Green, R. M., J. L. Fish, N. M. Young, F. J. Smith, B. Roberts, K. Dolan, I. Choi, C. L. Leach, P. Gordon, J. M. Cheverud, C. C. Roseman, T. J. Williams, R. S. Marcucio, and B. Hallgrímsson. 2017. Developmental nonlinearity drives phenotypic robustness. Nature Communications 8:1970.

Griffith, O. W., A. R. Chavan, S. Protopapas, J. Maziarz, R. Romero, and G. P. Wagner. 2017. Embryo implantation evolved from an ancestral inflammatory attachment reaction. Proceedings of the National Academy of Sciences 114:E6566.

Grochau-Wright, Z. I., E. R. Hanschen, P. J. Ferris, T. Hamaji, H. Nozaki, B. J. S. C. Olson, and R. E. Michod. 2017. Genetic basis for soma is present in undifferentiated volvocine green algae. Journal of Evolutionary Biology 30:1205-1218.

Hallgrimsson, B., R. M. Green, D. C. Katz, J. L. Fish, F. P. Bernier, C. C. Roseman, N. M. Young, J. M. Cheverud, and R. S. Marcucio. 2019. The developmental-genetics of canalization. Seminars in Cell \& Developmental Biology 88:67-79.

Helanterä, H. and T. Uller. 2020. Different perspectives on non-genetic inheritance illustrate the versatile utility of the Price equation in evolutionary biology. Philosophical Transactions of the Royal Society B: Biological Sciences 375:20190366.

Herrel, A., D. Joly, and E. Danchin. 2020. Epigenetics in ecology and evolution. Functional Ecology 34:381-384.

Herron, M. D., W. C. Ratcliff, J. Boswell, and F. Rosenzweig. 2018. Genetics of a de novo origin of undifferentiated multicellularity. Royal Society Open Science 5:180912.

Herron, M. D., J. M. Borin, J. C. Boswell, J. Walker, I. C. K. Chen, C. A. Knox, M. Boyd, F. Rosenzweig, and W. C. Ratcliff. 2019. De novo origins of multicellularity in response to predation. Scientific Reports 9:2328.

Hinton, G. E. and S. J. Nowlan. 1987. How learning can guide evolution. Complex Systems 1:495-502.

Hintze, M., S. L. Koneru, S. P. R. Gilbert, D. Katsanos, J. Lambert, and M. Barkoulas. 2020. A cell fate switch in the Caenorhabditis elegans seam cell lineage occurs through modulation of the Wnt asymmetry pathway in response to temperature increase. Genetics 214:927.

Hölldobler, B. and E. O. Wilson. 2009. The Superorganism: The Beauty, Elegance, and Strangeness of Insect Societies. W. W. Norton \& Company: New York.

Iglesias, P. P., E. M. Soto, I. M. Soto, B. Colines, and E. Hasson. 2018. The influence of developmental environment on courtship song in cactophilic Drosophila. Journal of Evolutionary Biology 31:957-967.

Jacobs, A., M. Carruthers, A. Yurchenko, N. V. Gordeeva, S. S. Alekseyev, O. Hooker, J. S. Leong, D. R. Minkley, E. B. Rondeau, B. F. Koop, C. E. Adams, and K. R. Elmer. 2020. Parallelism in eco-morphology and gene expression despite variable evolutionary and genomic backgrounds in a Holarctic fish. PLoS Genetics 16:e1008658.

Jamie, G. A., S. M. Van Belleghem, B. G. Hogan, S. Hamama, C. Moya, J. Troscianko, M. C. Stoddard, R. M. Kilner, and C. N. Spottiswoode. 2020. Multimodal mimicry of hosts in a radiation of parasitic finches. Evolution. 74:2526-2538. 
Jones, B. M. and G. E. Robinson. 2018. Genetic accommodation and the role of ancestral plasticity in the evolution of insect eusociality. The Journal of Experimental Biology 221:jeb153163.

Kapheim, K. M., B. M. Jones, H. Pan, C. Li, B. A. Harpur, C. F. Kent, A. Zayed, P. Ioannidis, R. M. Waterhouse, C. Kingwell, E. Stolle, A. Avalos, G. Zhang, W. O. McMillan, and W. T. Wcislo. 2020. Developmental plasticity shapes social traits and selection in a facultatively eusocial bee. Proceedings of the National Academy of Sciences 117:13615-13625.

Kelly, M. 2019. Adaptation to climate change through genetic accommodation and assimilation of plastic phenotypes. Philosophical Transactions of the Royal Society B: Biological Sciences 374:20180176.

Kieninger, M. R., N. A. Ivers, C. Rödelsperger, G. V. Markov, R. J. Sommer, and E. J. Ragsdale. 2016. The nuclear hormone receptor NHR-40 acts downstream of the sulfatase EUD-1 as part of a developmental plasticity switch in Pristionchus. Current Biology 26:2174-2179.

Klingenberg, C. P. 2019. Phenotypic plasticity, developmental instability, and robustness: The concepts and how they are connected. Frontiers in Ecology and Evolution 7:56.

Klironomos, F. D., J. Berg, and S. Collins. 2013. How epigenetic mutations can affect genetic evolution: Model and mechanism. Bioessays 35:571-578.

Kovaka, K. 2019. Underdetermination and evidence in the developmental plasticity debate. The British Journal for the Philosophy of Science 70:127-152.

Lafuente, E. and P. Beldade. 2019. Genomics of developmental plasticity in animals. Frontiers in Genetics 10:720.

Laland, K. N., F. J. Odling-Smee, and M. W. Feldman. 1999. Evolutionary consequences of niche construction and their implications for ecology. Proceedings of the National Academy of Sciences United States of America 96:10242-10247.

Laland, K. N., T. Uller, M. W. Feldman, K. Sterelny, G. B. Müller, A. P. Moczek, E. Jablonka, and J. Odling-Smee. 2015. The extended evolutionary synthesis: Its structure, assumptions and predictions. Proceedings of the Royal Society B: Biological Sciences 282:20151019.

Laland, K. N., F. J. Odling-Smee, and M. W. Feldman. 2019. Understanding niche construction as an evolutionary process, pp. 127-152. In T. Uller, and K. N. Laland, eds., Evolutionary Causation: Biological and Philosophical Reflections. MIT Press, Cambridge, MA.

Laundon, D., B. T. Larson, K. McDonald, N. King, and P. Burkhardt. 2019. The architecture of cell differentiation in choanoflagellates and sponge choanocytes. PLoS Biology 17:e3000226.

Le Rouzic, A. and Ö. Carlborg. 2008. Evolutionary potential of hidden genetic variation. Trends in Ecology \& Evolution 23:33-37.

Ledon-Rettig, C. C. and E. J. Ragsdale. 2021. Physiological mechanisms and the evolution of plasticity. In D. W. Pfennig, ed., Phenotypic Plasticity and Evolution: Causes, Consequences, Controversies. CRC Press, Boca Raton, FL.

Ledón-Rettig, C. C., D. W. Pfennig, A. J. Chunco, and I. Dworkin. 2014. Cryptic genetic variation in natural populations: a predictive framework. Integrative and Comparative Biology 54:783-793.

Levin, D. A. 2009. Flowering-time plasticity facilitates niche shifts in adjacent populations. New Phytologist 183:661-666.

Levis, N. A. and D. W. Pfennig. 2017. Phenotypic Plasticity. In K. Pfennig, ed., Oxford Bibliographies in Evolutionary Biology. Oxford University Press, New York. doi: 10.1093/OBO/9780199941728-0093.

Levis, N. A. and D. W. Pfennig. 2021. Innovation and diversification via plasticity-led evolution. In D. W. Pfennig, ed., Phenotypic Plasticity and Evolution: Causes, Consequences, Controversies. CRC Press, Boca Raton, FL. 
Levis, N. A., A. Serrato-Capuchina, and D. W. Pfennig. 2017. Genetic accommodation in the wild: Evolution of gene expression plasticity during character displacement. Journal of Evolutionary Biology 30:1712-1723.

Lewens, T. 2019. The extended evolutionary synthesis: What is the debate about, and what might success for the extenders look like? Biological Journal of the Linnean Society 127:707-721.

Mäkinen, H., T. Sävilammi, S. Papakostas, E. Leder, L. A. Vøllestad, and C. R. Primmer. 2017. Modularity facilitates flexible tuning of plastic and evolutionary gene expression responses during early divergence. Genome Biology and Evolution 10:77-93.

Mark, S., J. Weiss, E. Sharma, T. Liu, W. Wang, J. M. Claycomb, and A. D. Cutter. 2019. Genome structure predicts modular transcriptome responses to genetic and environmental conditions. Molecular Ecology:517235.

McNett, G. D. and R. B. Cocroft. 2008. Host shifts favor vibrational signal divergence in Enchenopa binotata treehoppers. Behavioral Ecology 19:650-656.

Michimae, H. and T. Emura. 2012. Correlated evolution of phenotypic plasticity in metamorphic timing. Journal of Evolutionary Biology 25:1331-1339.

Moczek, A. P. 2006. Integrating micro- and macroevolution of development through the study of horned beetles. Heredity 97:168-178.

Moczek, A. P. 2008. On the origin of novelty in development and evolution. Bioessays 5:432-447.

Moczek, A. P., J. Hunt, D. J. Emlen, and L. W. Simmons. 2002. Threshold evolution in exotic populations of a polyphenic beetle. Evolutionary Ecology Research 4:587-601.

Moczek, A. P., S. Sultan, S. Foster, C. Ledon-Rettig, I. Dworkin, H. F. Nijhout, E. Abouheif, and D. W. Pfennig. 2011. The role of developmental plasticity in evolutionary innovation. Proceedings of the Royal Society B-Biological Sciences 278:2705-2713.

Moser, D., B. Kueng, and D. Berner. 2015. Lake-stream divergence in stickleback life history: A plastic response to trophic niche differentiation? Evolutionary Biology 42:328-338.

Müller, G. B. 2007. Evo-Devo: Extending the evolutionary synthesis. Nature Reviews Genetics 8:943-949.

Müller, G. B. 2019. Evo-Devo's contributions to the extended evolutionary synthesis, pp. 1-12. In L. Nuno de la Rosa, and G. Müller, eds. Evolutionary Developmental Biology: A Reference Guide. Springer International Publishing, New York.

Murren, C. J., H. J. Maclean, S. E. Diamond, U. K. Steiner, M. A. Heskel, C. A. Handelsman, C. K. Ghalambor, J. R. Auld, H. S. Callahan, D. W. Pfennig, R. A. Relyea, C. D. Schlichting, and J. Kingsolver. 2014. Evolutionary change in continuous reaction norms. American Naturalist 183:453-467.

Namdeo, S., E. Moreno, C. Rödelsperger, P. Baskaran, H. Witte, and R. J. Sommer. 2018. Two independent sulfation processes regulate mouth-form plasticity in the nematode Pristionchus pacificus. Development 145:dev166272.

Newman, S. A. and G. B. Müller. 2000. Epigenetic mechanisms of character origination. Journal of Experimental Zoology (Molecular and Developmental Evolution) 288:304-317.

Nijhout, H. F. 1990. Problems and paradigms: Metaphors and the roles of genes in development. Bioessays 12:441-446.

Nijhout, H. F. 2003. Development and evolution of adaptive polyphenisms. Evolution \& Development 5:9-18.

Nijhout, H. F., F. Sadre-Marandi, J. Best, and M. C. Reed. 2017. Systems biology of phenotypic robustness and plasticity. Integrative and Comparative Biology 57:171-184.

Nijhout, H. F., J. A. Best, and M. C. Reed. 2019. Systems biology of robustness and homeostatic mechanisms. Wiley Interdisciplinary Reviews: Systems Biology and Medicine 11:e1440. 
Noble, D. W. A., R. Radersma, and T. Uller. 2019. Plastic responses to novel environments are biased towards phenotype dimensions with high additive genetic variation. Proceedings of the National Academy of Sciences 116:201821066.

Okada, Y., Y. Watanabe, M. M. Y. Tin, K. Tsuji, and A. S. Mikheyev. 2017. Social dominance alters nutrition-related gene expression immediately: Transcriptomic evidence from a monomorphic queenless ant. Molecular Ecology 26:2922-2938.

Osborne, O. G., A. Ciezarek, T. Wilson, D. Crayn, I. Hutton, W. J. Baker, C. G. N. Turnbull, and V. Savolainen. 2019. Speciation in Howea palms occurred in sympatry, was preceded by ancestral admixture, and was associated with edaphic and phenological adaptation. Molecular Biology and Evolution 36:2682-2697.

Otte, T., M. Hilker, and S. Geiselhardt. 2018. Phenotypic plasticity of cuticular hydrocarbon profiles in insects. Journal of Chemical Ecology 44:235-247.

Paaby, A. B. and M. V. Rockman. 2014. Cryptic genetic variation: Evolution's hidden substrate. Nature Reviews Genetics 15:247-258.

Parsons, K. J., M. R. Concannon, D. Navon, J. Wang, I. Ea, K. Groveas, C. Campbell, and R. C. Albertson. 2016. Foraging environment determines the genetic architecture and evolutionary potential of trophic morphology in cichlid fishes. Molecular Ecology 25:6012-6023.

Parsons, K. J., K. McWhinnie, N. Pilakouta, and L. Walker. 2020. Does phenotypic plasticity initiate developmental bias? Evolution \& Development 22:56-70.

Payne, J. L. and A. Wagner. 2019. The causes of evolvability and their evolution. Nature Reviews Genetics 20:24-38.

Pei, Y., W. Forstmeier, and B. Kempenaers. 2020. Offspring performance is well buffered against stress experienced by ancestors. Evolution 74:1525-1539.

Peichel, C. L. and D. A. Marques. 2017. The genetic and molecular architecture of phenotypic diversity in sticklebacks. Proceedings of the Royal Society B-Biological Sciences 372:2015.0486.

Pespeni, M. H., J. T. Ladner, and A. P. Moczek. 2017. Signals of selection in conditionally expressed genes in the diversification of three horned beetle species. Journal of Evolutionary Biology 30:1644-1657.

Pfennig, D. W. 2021. Key questions about phenotypic plasticity. In D. W. Pfennig, ed., Phenotypic Plasticity and Evolution: Causes, Consequences, Controversies. CRC Press, Boca Raton, FL.

Pfennig, D. W. and K. S. Pfennig. 2012. Development and evolution of character displacement. Annals of the New York Academy of Sciences 1256:89-107.

Pfennig, D. W., A. M. Rice, and R. A. Martin. 2007. Field and experimental evidence for competition's role in phenotypic divergence. Evolution 61:257-271.

Pfennig, D. W., M. A. Wund, E. C. Snell-Rood, T. Cruickshank, C. D. Schlichting, and A. P. Moczek. 2010. Phenotypic plasticity's impacts on diversification and speciation. Trends in Ecology \& Evolution 25:459-467.

Pigliucci, M. 2007. Do we need an extended evolutionary synthesis? Evolution 61:2743-2749.

Pilakouta, N., S. S. Killen, B. K. Kristjánsson, S. Skúlason, J. Lindström, N. B. Metcalfe, and K. J. Parsons. 2020. Multigenerational exposure to elevated temperatures leads to a reduction in standard metabolic rate in the wild. Functional Ecology 34:1205-1214.

Ragsdale, E. J. and N. A. Ivers. 2016. Specialization of a polyphenism switch gene following serial duplications in Pristionchus nematodes. Evolution 70:2155-2166.

Rajakaruna, N., G. E. Bradfield, B. A. Bohm, and J. Whitton. 2003. Adaptive differentiation in response to water stress by edaphic races of Lasthenia californica (Asteraceae). International Journal of Plant Sciences 164:371-376.

Ratcliff, W. C., J. D. Fankhauser, D. W. Rogers, D. Greig, and M. Travisano. 2015. Origins of multicellular evolvability in snowflake yeast. Nature Communications 6:6102. 
Ratcliff, W. C., M. Herron, P. L. Conlin, and E. Libby. 2017. Nascent life cycles and the emergence of higher-level individuality. Philosophical Transactions of the Royal Society B: Biological Sciences 372:20160420.

Relyea, R. A., P. R. Stephens, L. N. Barrow, A. R. Blaustein, P. W. Bradley, J. C. Buck, A. Chang, J. P. Collins, B. Crother, J. Earl, S. S. Gervasi, J. T. Hoverman, O. Hyman, E. M. Lemmon, T. M. Luhring, M. Michelson, C. Murray, S. Price, R. D. Semlitsch, A. Sih, A. B. Stoler, N. VandenBroek, A. Warwick, G. Wengert, and J. I. Hammond. 2018. Phylogenetic patterns of trait and trait plasticity evolution: Insights from amphibian embryos. Evolution 72:663-678.

Rendel, J. M. 1967. Canalisation and Gene Control. Logos Press, London.

Rice, S. H. 2020. Universal rules for the interaction of selection and transmission in evolution. Philosophical Transactions of the Royal Society B: Biological Sciences 375:20190353.

Rivera-Yoshida, N., A. V. Arzola, J. A. Arias Del Angel, A. Franci, M. Travisano, A. E. Escalante, and M. Benítez. 2019. Plastic multicellular development of Myxococcus xanthus: Genotype-environment interactions in a physical gradient. Royal Society Open Science 6:181730.

Robinson, B. W. and D. W. Pfennig. 2013. Inducible competitors and adaptive diversification. Current Zoology 59:537-552.

Rodriguez, R. L., L. Sullivan, R. Snyder, and R. B. Cocroft. 2008. Host shifts and the beginning of signal divergence. Evolution 62:12-20.

Rohner, P. T. and A. P. Moczek. 2020. Rapid differentiation of plasticity in life history and morphology during invasive range expansion and concurrent local adaptation in the horned beetle Onthophagus taurus. Evolution 74:2059-2072.

Rollo, C. D. 1994. Phenotypes: Their Epigenetics, Ecology and Evolution. Chapman and Hall, London.

Rossiter, M. C. 1996. Incidence and consequences of inherited environmental effects. Annual Review of Ecology and Systematics 27:451-476.

Rowinski, P. K. and B. Rogell. 2017. Environmental stress correlates with increases in both genetic and residual variances: A meta-analysis of animal studies. Evolution 71:1339-1351.

Rusman, Q., D. Lucas-Barbosa, and E. H. Poelman. 2018. Dealing with mutualists and antagonists: Specificity of plant-mediated interactions between herbivores and flower visitors, and consequences for plant fitness. Functional Ecology 32:1022-1035.

Sachs, T. 2002. Consequences of the inherent developmental plasticity of organ and tissue relations. Evolutionary Ecology 16:243-265.

Salazar-Ciudad, I., M. Marín-Riera, and M. Brun-Usan. 2019. The relationship between genetics, epigenetics and epigenesis in evolution and development, pp. 369-378. In G. Fusco, ed., Perspectives on Evolutionary and Developmental Biology. Padova University Press, Padova, Italy.

Samani, P. and G. Bell. 2016. The ghosts of selection past reduces the probability of plastic rescue but increases the likelihood of evolutionary rescue to novel stressors in experimental populations of wild yeast. Ecology Letters 19:289-298.

Sattman, D. A. and R. B. Cocroft. 2003. Phenotypic plasticity and repeatability in the mating signals of Enchenopa treehoppers, with implications for reduced gene flow among host-shifted populations. Ethology 109:981-994.

Scheiner, S. M. and N. A. Levis. 2021. The loss of phenotypic plasticity via natural selection: Genetic assimilation. In D. W. Pfennig, ed., Phenotypic Plasticity and Evolution: Causes, Consequences, Controversies. CRC Press, Boca Raton, FL.

Schlichting, C. D. 1989. Phenotypic integration and environmental change. Bioscience 39:460-464.

Schlichting, C. D. 2003. The origins of differentiation via phenotypic plasticity. Evolution \& Development 5:98-105. 
Schlichting, C. D. 2004. The role of phenotypic plasticity in diversification, pp. 191-200. In T. J. DeWitt, and S. M. Scheiner, eds., Phenotypic Plasticity: Functional and Conceptual Approaches. Oxford University Press, Oxford.

Schlichting, C. D. 2008. Hidden reaction norms, cryptic variation and evolvability. Annals of the New York Academy of Science 1133:187-203.

Schlichting, C. D. and C. J. Murren. 2004. Evolvability and the raw materials for adaptation, pp. 18-29. In Q. C. B. Cronk, J. Whitton, R. H. Ree, and I. E. P. Taylor, eds., Molecular Genetics and Ecology of Plant Adaptation. NRC Research Press, Ottawa, Ontario.

Schlichting, C. D. and M. Pigliucci. 1998. Phenotypic Evolution: A Reaction Norm Perspective. Sinauer Associates, Sunderland, MA.

Schlichting, C. D. and H. Smith. 2002. Phenotypic plasticity: Linking molecular mechanisms with evolutionary outcomes. Evolutionary Ecology 16:189-211.

Schlichting, C. D. and M. A. Wund. 2014. Phenotypic plasticity and epigenetic marking: An assessment of evidence for genetic accommodation. Evolution 68:656-672.

Schmalhausen, I. I. 1949. Factors of Evolution. Blakiston, Philadelphia, PA.

Schneider, R. F. and A. Meyer. 2017. How plasticity, genetic assimilation and cryptic genetic variation may contribute to adaptive radiations. Molecular Ecology 26:330-350.

Schou, M. F., A. A. Hoffmann, and T. N. Kristensen. 2019. Genetic correlations and their dependence on environmental similarity: Insights from livestock data. Evolution 73:1672-1678.

Schwab, D. B., S. Casasa, and A. P. Moczek. 2019. On the reciprocally causal and constructive nature of developmental plasticity and robustness. Frontiers in Genetics 9:735.

Sieriebriennikov, B. and R. J. Sommer 2018. Developmental plasticity and robustness of a nematode mouth-form polyphenism. Frontiers in Genetics 9:382.

Signor, S. A. 2020. Evolution of phenotypic plasticity in response to ethanol between sister species with different ecological histories (Drosophila melanogaster and D. simulans). American Naturalist 196:620-633.

Sikkink, K. L., R. M. Reynolds, C. M. Ituarte, W. A. Cresko, and P. C. Phillips. 2019. Environmental and evolutionary drivers of the modular gene regulatory network underlying phenotypic plasticity for stress resistance in the nematode Caenorhabditis remanei. G3: Genes|Genomes|Genetics 9:969-982.

Silva-Brandão, K. L., R. J. Horikoshi, D. Bernardi, C. Omoto, A. Figueira, and M. M. Brandão. 2017. Transcript expression plasticity as a response to alternative larval host plants in the speciation process of corn and rice strains of Spodoptera frugiperda. BMC Genomics 18:792.

Smith, H. 1990. Signal perception, differential expression within multigene families and the molecular basis of phenotypic plasticity. Plant, Cell and Environment 13:585-594.

Smith, G., Y. X. Fang, X. Liu, J. Kenny, A. R. Cossins, C. C. de Oliveira, W. J. Etges, and M. G. Ritchie. 2013. Transcriptome-wide expression variation associated with environmental plasticity and mating success in cactophilic Drosophila mojavensis. Evolution 67:1950-1963.

Snell-Rood, E. C., J. D. Van Dyken, T. Cruickshank, M. J. Wade, and A. P. Moczek. 2010. Toward a population genetic framework of developmental evolution: The costs, limits, and consequences of phenotypic plasticity. BioEssays 32:71-81.

Sommer, R. J., M. Dardiry, M. Lenuzzi, S. Namdeo, T. Renahan, B. Sieriebriennikov, and M. S. Werner. 2017. The genetics of phenotypic plasticity in nematode feeding structures. Open Biology 7:160332.

Sorenson, M. D., K. M. Sefc, and R. B. Payne. 2003. Speciation by host switch in brood parasitic Indigobirds. Nature 424:928-931.

Stearns, F. W., K. J. Tilmon, and T. K. Wood. 2013. Felsenstein's "one-allele model” of speciation: The role of philopatry in the initial stages of host plant mediated reproductive isolation in Enchenopa binotata. Current Zoology 59:658-666. 
Stennett, M. D. and W. J. Etges. 1997. Premating isolation is determined by larval rearing substrates in Cactophilic Drosophila mojavensis. III. Epicuticular hydrocarbon variation is determined by use of different host plants in Drosophila mojavensis and Drosophila arizonae. Journal of Chemical Ecology 23:2803-2824.

Sultan, S. E. 2015. Organism and Environment: Ecological Development, Niche Construction and Adaptation. Oxford University Press, Oxford.

Sultan, S. E. 2017. Developmental plasticity: Re-conceiving the genotype. Interface Focus 7:20170009.

Sultan, S. E. 2021. Phenotypic plasticity as an intrinsic property of organisms. In D. W. Pfennig, ed., Phenotypic Plasticity and Evolution: Causes, Consequences, Controversies. CRC Press, Boca Raton, FL.

Sun, P., G. Li, J. Jian, L. Liu, J. Chen, S. Yu, H. Xu, C. Lei, X. Zhou, and Q. Huang. 2019. Transcriptomic and functional analyses of phenotypic plasticity in a higher termite, Macrotermes barneyi light. Frontiers in Genetics 10:964.

Susoy, V., M. Herrmann, N. Kanzaki, M. Kruger, C. N. Nguyen, C. Rödelsperger, W. Röseler, C. Weiler, R. M. Giblin-Davis, E. J. Ragsdale, and R. J. Sommer. 2016. Large-scale diversification without genetic isolation in nematode symbionts of figs. Science Advances 2:e1501031.

Svensson, E. I. 2018. On reciprocal causation in the evolutionary process. Evolutionary Biology 45:1-14.

Taylor, R. S. and V. L. Friesen. 2017. The role of allochrony in speciation. Molecular Ecology 26:3330-3342.

Uller, T., A. P. Moczek, R. A. Watson, P. M. Brakefield, and K. N. Laland. 2018. Developmental bias and evolution: A regulatory network perspective. Genetics 209:949-966.

Uller, T., N. Feiner, R. Radersma, I. S. C. Jackson, and A. Rago. 2020. Developmental plasticity and evolutionary explanations. Evolution \& Development 22:47-55.

van Gestel, J. and F. J. Weissing. 2016. Regulatory mechanisms link phenotypic plasticity to evolvability. Scientific Reports 6:24524.

Velotta, J. P. and Z. A. Cheviron. 2018. Remodeling ancestral phenotypic plasticity in local adaptation: A new framework to explore the role of genetic compensation in the evolution of homeostasis. Integrative and Comparative Biology 58:1098-1110.

Velotta, J. P., C. M. Ivy, C. J. Wolf, G. R. Scott, and Z. A. Cheviron. 2018. Maladaptive phenotypic plasticity in cardiac muscle growth is suppressed in high-altitude deer mice. Evolution 72:2712-2727.

Waddington, C. H. 1953. Epigenetics and evolution. Symposia of the Society for Experimental Biology 7:186-199.

Wagner, A. 2005. Robustness, evolvability, and neutrality. FEBS Letters 579:1772-1778.

Wagner, G. P. and L. Altenberg. 1996. Perspective: Complex adaptations and the evolution of evolvability. Evolution 50:967-976.

Wagner, G. P., E. M. Erkenbrack, and A. C. Love. 2019. Stress-induced evolutionary innovation: A mechanism for the origin of cell types. BioEssays 41:1800188.

Wcislo, W. T. 1989. Behavioral environments and evolutionary change. Annual Review of Ecology and Systematics 20:137-170.

West-Eberhard, M. J. 1989. Phenotypic plasticity and the origins of diversity. Annual Review of Ecology and Systematics 20:249-278.

West-Eberhard, M. J. 2003. Developmental Plasticity and Evolution. Oxford University Press, New York.

West-Eberhard, M. J. 2005. Developmental plasticity and the origin of species differences. Proceedings of the National Academy of Sciences 102:6543-6549.

Wolinsky, E. and E. Libby. 2016. Evolution of regulated phenotypic expression during a transition to multicellularity. Evolutionary Ecology 30:235-250. 
Wood, C. W. and E. D. Brodie III. 2015. Environmental effects on the structure of the $G$-matrix. Evolution 69:2927-2940.

Wood, T. K. and S. I. Guttman. 1982. Ecological and behavioral basis for reproductive isolation in the sympatric Enchenopa binotata complex (Homoptera, Membracidae). Evolution 36:233-242.

Wray, G. A., H. E. Hoekstra, D. J. Futuyma, R. E. Lenski, T. F. C. Mackay, D. Schluter, and J. E. Strassmann. 2014. Does evolutionary theory need a rethink? No, all is well. Nature 514:161-164.

Wright, S. 1931. Evolution in Mendelian populations. Genetics 16:97-159.

Wright, J., G. H. Bolstad, Y. G. Araya-Ajoy, and N. J. Dingemanse. 2018. Life-history evolution under fluctuating density-dependent selection and the adaptive alignment of paceof-life syndromes. Biological Reviews, 94(1): 230-247.

Zan, Y. and Ö. Carlborg. 2020. Dynamic genetic architecture of yeast response to environmental perturbation shed light on origin of cryptic genetic variation. PLoS Genetics 16:e1008801.

Zheng, J., J. L. Payne, and A. Wagner. 2019. Cryptic genetic variation accelerates evolution by opening access to diverse adaptive peaks. Science 365:347-353. 